\title{
Examining Factors that MA Students face while conducting their Theses: The Case of School of Education and behavioral Sciences, Wolaita Sodo University.
}

\author{
Tafano Ouke Labiso \\ (Assistant Professor) \\ Department of Educational Planning and Management, \\ Wolaita Sodo University, Ethiopia
}

\begin{abstract}
The purpose of this study was to dig out the root causes for the challenges that MA/or second degree students face while conducting the research(Theses). Hence, to realize and achieve this purpose, qualitative case study research method and design respectively were employed. Both primary sources and secondary sources were employed. The primary sources were 40 regular and summer MA students, and the secondary sources were the Theses materials of 4 years. Simple random sampling technique was used to select 40 Theses materials out of the 4 year batches. Observation and document analysis were made to collect data. Data were analyzed qualitatively through narration. The findings showed that there was the knowledge gap on the part of the researchers about the fundamentals of research on one hand and on the other hand the concerned bodies gave little attention for capacitating the researchers, and also gave low attention for monitoring the progress of the researchers while conducting research. And it could be concluded that there were a lot of activities that the concerned bodies like school of graduate studies, heads and deans of the departments and schools or colleges, academic vice presidents, and even instructors have to do to capacitate the researchers or MA students. Therefore, it was suggested that statistical courses should be integrated with research courses and also there should be the content regarding advanced analysis of the findings, and also the training for the students should be strengthened and also there should be monitoring and evaluation system developed.
\end{abstract}

Key words: challenge; MA students; Thesis, research

\section{INTRODUCTION}

Research is a well- planned, systematically organized investigation, related to a certain topic and methodology, aiming at collecting valuable data and analyzing it in the context of a certain framework (Cohen, 1980). This works for the master's theses or dissertation as well which are types of research. It is evident that all universities throughout the globe use theses as the criteria for partial fulfillment of their degrees regardless of their type, except some non-thesis degrees in some emerging universities of the world (Baron, 2010). The importance of theses is not questionable, because it is obvious that individual graduates are expected to conduct a number of researches to solve different existing problems of the society and also to come with novel ideas through conducting different types of researches-applied or basic (Gay et al., 2012). Hence, more attention and weigh are given for theses work. So, in different higher education institutions it is taken as one of the criteria for graduation. Hence, in order to realize this purpose, different universities prepare the guideline including some essential elements in it. Furthermore, they provide a number of orientations for their students about the theses works via the advisors. And also the students are made to be advised and take research courses by highly trained and professional researchers. They give more focus for the research 
work than the course work. So, many countries and universities of the world have many experiences and practices regarding this. They are well equipped both materially and in human capital as well. They do not face such a problem regarding the research work because their systems are well developed.

However, underdeveloped and developing countries face a number of challenges regarding the research work (Best \& Kahn., 2003). They have no well -developed research institutions and system as well. No more and highly trained man power in advanced research. No adequate materials and financial resources available. No professional leaders in research are assigned to lead and manage the system. Both institutions and individuals have low interest and experience in running such programs. Individuals are assigned to run this program only because they are qualified. No attention is made for their specialization-those who assign the heads for such units give less attention or no attention for the specialization in research. Wolaita Sodo University is no exception.

Wolaita Sodo University was established in 2007 with a few faculties, departments, instructors, offices, classrooms, supportive staffs, and a few students (Office of communication (WSU), 2018). During that time there was no research coordination office, research policies and guidelines. Some years later, office for research and community services under the vice president for academic and research was opened. Recently, there are office of vice president for research and community services, research and community service directors under the vice president for research and community services, research and community services coordinators with each colleges and schools, research and community services guidelines and policies of the university, and also school of graduate studies that give more focus to research works of the graduates along with other activities. And also thousands of students have graduated with their second degrees in different areas of specialization including educational leadership and management specialization till today. However, when examined thoroughly, many of the researches-theses were found to suffer a lot in quality graduates suffered a lot while defending their theses. Hence, the researcher was impressed and determined to conduct a research on the issue under study.

\section{Statement of the problem}

Experiences and long- time observations showed that there were a lot of problems around the theses work of second degree students of school of education and behavioral sciences, Wolaita Sodo University. There observed and examined a lot of problems with the MA theses and challenges that postgraduate students faced while defending their theses. Theses of both regular and weekend students in the department of Educational Leadership and Management in the school of Education and Behavioral Sciences, during different times have got a number of problems.. However, there was no attempt to make research and to solve such a problem both at the school of Education and Behavioral sciences.. Even it seemed that as if the quality issue of research has been ignored by all the research concerned individuals. Thus, what the author of this research observed, while advising and examining during different times impressed him to conduct this research. Therefore, the following basic questions were designed to dig out and examine the existing problems to the low quality of Thesis works and also low performance of the graduates:

1. What are the causes for the low performance of MA students in their Theses?

2. Which ones are the most serious ones?

3. Is there any attempt made earlier to tackle the problem by the concerned bodies? 


\section{Objective}

The objective of this study was to tackle the problems that likely reduced the quality of the MA Theses at the school of education and behavioral sciences.

\section{Significance of the study}

$>$ It may help the policy designers of research and community service of the university and school of graduate study and others concerned with research work;

$>$ It may be used as a guide for the students of all types and levels as a reference and guideline

$>$ It is hoped to show what to do and how to do regarding researches for the heads of researches at different levels

$>$ It may be used as a reference for further study and also as locus of literature. Because nobody was seen attempting to solve such problems in the area of theses.

$>$ Other colleges too, may benefit from the findings as well since in many aspects they are the same.

\section{Scope of the study}

The study was geographically delimited to the school of Education and Behavioral Sciences regular and weekend MA students, and conceptually to the challenges that MA students face.

\section{LITERATURE REVIEW \\ Concepts, Natures and Advantages of Elements of the MA Thesis}

In many universities of the world, five chapters are used with the MA/or MSc Theses which consists of the preliminary part, the main body, and the appendices sections. Cover pages, interior page, the examining board approval page, copyright page, table of contents, list of figures, list of tables, acknowledgements, abstract or executive summary, dedication, declaration, acronyms and or abbreviations etc. are some of the major parts or elements of the preliminary section of the Thesis (Baron, 2010). The pages of these parts are usually written in small roman numbers except the cover page and immediate interior page. Though no page number is printed on the cover and immediate interior pages, however, they are counted as page numbers one and two (Baron, 2010). Each part is expected to be written up to standard. The next part is the main body. It consists of the introduction or sometimes called problem and the approaches - that is chapter one; review of the related or relevant literature. This consists of both new and old, but still relevant sources with the topic under study. It is all about who said what in the relevant literature about the topic under study. Here, researchers are advised to use the most relevant and standardized, reputable, and professional materials-books, journal articles, magazines and so on. Researchers are also advised to review exhaustively taking in to account more could be learnt while reviewing different works of gurus in the area of specialization. Chapter three refers to the research design and methodology. This is where the potential sources of data are clearly mentioned, target population is clearly cited, sample size is determined, and sampling techniques applied or to be applied are clearly mentioned for others. Moreover, research design and research method are clearly explained here. Researchers most of the time, confuse research design with research method. Whereas research method refers to qualitative or quantitative nature of data, research design refers to the overall plan of the research. Data collection and analysis tool are also mandatory to be cited here. Data collection tools (for both quantitative and qualitative) like different types of questionnaires, interviews, focus group discussion, observations, document analysis are mentioned here. Whether descriptive or inferential, statistical tools to be used, are mentioned here. Variables-both dependent and independent, ethical consideration, confirm ability, reliability and validity issues, trustworthiness issues etc should be mentioned here accordingly with both quantitative and qualitative researches. Chapter four deals with the discussion of the 
findings where the collected data are presented, analyzed and interpreted using tables, graphs, charts, circles etc. and where analysis is made using those standard analysis tools(both descriptive and inferential)based on the nature of the data and where the qualitative data are narrated. The last chapter is chapter five. This consists of summary of the major findings, conclusions, and recommendations. This of course lacks sometimes uniformity according to different universities and the number of chapters increases when one moves from senior essay to the $\mathrm{PhD}$ dissertation. And what come next are the bibliography and /or reference. This too, is taken as the main body on the part of many scholars. Bibliography is written if both the written and unwritten sources are used for writing the material. Reference is used or written as a heading if only the mentioned sources in the material is to be cited. Furthermore, citation is made alphabetically, exhaustively with all its elements using the international and standardized styles of citation like APA (American Psychological Association), Harvard, Michigan, MLA(Gay, 2012), etc. Of course, this varies sometimes as the discipline or nature of the field. In most cases social sciences and education researches use APA style and natural and hard sciences use Harvard style.

The last part of the thesis is appendices/or appendixes part. This is an essential but not this much significant part. It is where all the sample data collection tools, large tables, letters etc. are written. It is written on the back side of the report paper(Wassenaar, 2010).. Almost many parts of the report materials are written in the past tense except the chapter outline part or organization of the study part-that takes simple present tense most of the time. Only the main body of the material is paginated by Arabic number. Both the preliminary part and appendix part take Roman numbers for their pagination. The cover page and interior pages to the cover pages do not take page number.

Plagiarism or intellectual theft is one of the serious problems nowadays (Gay, 2012). Scholars are advised most of the time to do their original works. Though it is not denied that ideas of different people may be similar to some extent; however, it is not encouraged to copy the original works of others as if they did it. This is both un ethical, immoral, illegal and punishable by law. Furthermore one cannot learn anything if he/she does copy directly from someone else's work. Rather, he or she can quote and paraphrase in his or her work somebody's ideas.

\section{RESEARCH DESIGN AND METHODOLOGY}

Case study research design and qualitative method of data collection were employed.

\section{Source of data}

Both primary and secondary sources were employed. The primary sources were the MA candidates of school of Education and behavioral sciences of 4 years. The secondary sources were MA documents or thesis of 40 candidates, and notes taken while they were defending their theses.

\section{Population, sample and sampling technique}

The 4 batches (regular and weekend) MA graduates of school of Education and Behavioral sciences.

\section{Data Collection Tools}

Observation notes of the defense presentations and theses materials of 40 students from 4 batches), and also the guideline of the school of graduate studies and format were employed to collect data. 


\section{Data Analysis Tools}

All qualitative data obtained through observation notes, school of graduate studies format and guideline, and document analysis were used properly

\section{FINDINGS AND DISCUSSIONS}

All parts of the materials (from the preliminary to the reference) and their presentations have been examined and observed and the problems were found as follows:

$>$ The school of graduate study format has got a problem that is ambiguous particularly on its preliminary part;

$>$ It was found that students failed how to write the abstract and its fundamental elements, its size and length, spacing, font size and style as well.

$>$ Only the major issues are written under the content part. However, majority of the papers have been observed that table of contents were written in a too detailed way;

$>$ The acknowledgements part was not written up to standard-it is written in a disordered way and missing some elements, and suffered a lot from editing problem;

$>$ Introductory parts of many theses failed to mention the background of the study; failed to provide the readers with brief summary of literature and research; and failed to lead up to the statement of the problem;

$>$ Both writing and speaking skills were observed to have been suffered a lot;

$>$ Statements of the problems failed to show the gap of the problems, the reasons for the selection of the topic, and if there were researches conducted before or not were not mentioned with most of the materials of the candidates;

$>$ Many couldn't distinguish between the general and specific objectives;

$>$ Some couldn't show the significance of the study and even did't seem to have been familiar with it meaning;

$>$ Some couldn't seem to have distinguished between the key terms and operational terms, and even about the importance of them;

$>$ A number of materials failed to have used tenses wrongly-they used future tenses with their report;

$>$ Literature reviews of most of the papers seemed to be as if written for the sake of writing. Nothing inferred to it throughout the paper. They wrote it and failed to consult and refer it while they were analyzing and interpreting and discussing the findings;

$>$ Some wrote the irrelevant subtopics to the major topics of their problems, and seemingly didn't review exhaustively and, and even they didn't seem they have learnt a lot while reviewing the works of different gurus;

$>$ Some couldn't understand the elements of theses after all, because some fundamental elements were missing with some of the theses materials by the researchers;

$>$ There was confusion on the use of data presentation and analysis that some used analysis instead of presentation and vice versa;

$>$ Some failed to support the findings with literature part and analysis tools;.

$>$ The majority failed to use advanced analysis tools that could have indicated the real truth about the problems understudy - they used only descriptive statistical tools;

$>$ Summary of the major findings were not clear with some theses---there was no difference between summary of the major findings and discussion;

$>$ Majority's paper lacked clarity on conclusion-confusion on conclusion and summary of the major findings was observed

$>$ Researchers' materials were observed to command individuals rather than forwarding their suggestions smoothly to the concerned bodies;

$>$ They failed to cite the right sources using the standard citation styles like APA, Harvard, MLA etc. 
$>$ Some failed to acknowledge the sources alphabetically, and missed some important elements;

$>$ There were pagination, citation, font size, spacing, marginalization, and editing problems;

$>$ Fear of presenting and language problems were examined and observed; and also lack of confidence while defending their theses that they had already done were observed;

$>$ Lack of attempt to conduct original research; plagiarism and directly or indirectly copying someone else's previous work at other or same university was observed ;

$>$ Whereas the proposal of the research is written in the future and present tenses, the report is written in past tenses. However, thirty materials were seen to have used the future tense with the report of the work.

$>$ Power point using problem even to present what they had done;

$>$ Listening problem to take comments while the examiners were commenting on their presentation and their materials were observed during their defense session;

$>$ Failure to distinguish between reading and presenting was observed-majority of the researchers were observed to have read their paper than present it;

$>$ The use of outdated and irrelevant materials for literature review was the problem;

$>$ Failure to use diagram, charts, circles and so on for attractive presentation of data was found to be the problem;

$>$ The use of irrelevant and simple descriptive statistical tools for analysis factors with all types of research title was another problem;

$>$ Confusion between limitations, scope and delimitation of the study were found to be another serious problem;

$>$ Failure to distinguish between acronyms and abbreviations was also another problem of majority of the theses;

$>$ Some advisors and examiners were observed to have advised and examined more than what the guideline allows to do so , and against the research policy of the university.

\section{CONCLUSIONS}

$>$ Majority of the respondents responded that and observed for using simple descriptive statistics in un proper ways. Thus, this indicated that advanced training on advanced research tools were mandatory for both the instructors and students of post graduate level.

$>$ Some of the problems observed during many sessions of defense presentation were found to be related with the advisors, school of graduate studies, and the university as well. Hence, this indicated that there should be progress monitoring and evaluation system, and also the right capacity building trainings provided for leaders, instructors, and students of this level regarding research works.

$>$ It was found that most of the advisors were from far away universities and from different areas of specialization. That indicated that advisors should be assigned from within the institution or nearby institutions, and also there should be the right advisors from the same area of specialization.

$>$ Some of the candidates didn't use the right format of the university. This indicated that there was a need for the revision of SGS or (school of graduate studies guideline) and availability of the guideline at departments, schools or colleges and libraries as well.

$>$ Some advisors and examiners were observed to have done more than what the guideline allows and against the research policy of the university. That indicated that the rules and regulations pertaining to research were violated.

$>$ There observed editing and other language related problems throughout many of the theses materials. This indicated that there was knowledge gap regarding language and 
no training was given for the candidates about the technical languages related with research.

$>$ It is concluded that there indicated that the financial, material, and time inadequacy, along with the commitment problems of research leaders at different level and colleges to conduct quality research were the serious problems.

$>$ It is about 11 years since wolaita sodo university is established as a university. However, there are a lot of gaps regarding thesis works, including the guidelines of research and professional knowledge and skill of instructors and students of this level as well. Hence, this indicates that low attempt was made for improving research work.

\section{RECOMMENDATIONS}

$>$ Courses of statistics are related in many ways with research courses. Therefore, Statistical courses should be incorporated in the MA courses;

$>$ Topics about advanced research tools and their application should be incorporated in the research course of post graduate program;

$>$ There observed the knowledge gap on the part of students regarding how to conduct a research at this level. Therefore, it is better if the right instructors are assigned for research courses;

$>$ It is better if instructors assigned for the research courses teach in the way that may help post graduate students in their thesis works later on;

$>$ Short training about the use of SPSS and other soft wares should be offered through the process;

$>$ It seems better if all the relevant research guidelines and reference materials are available at laboratories, libraries and even at departments, colleges and schools;

$>$ Internet should be available 24 hours where students can work their research;

$>$ It is better if there are mock exams so that to make their materials improved and rehearse how to properly present what they conducted and found later on;

$>$ There should be non-ambiguous and up to standard SGS(school of graduate studies) guidelines;

$>$ The respective departments should avail the research guidelines and also should give adequate orientation about the thesis works, and those who assumed the leadership positions of those respective departments should be the right persons with the right knowledge and skill to shoulder such big responsibility starting from departments through research vice presidents;

$>$ Up-to-date research materials should be available at both the libraries and departments;

$>$ There should be safe and separate study rooms, particularly, for the researchers at post graduate levels;

$>$ The right persons should be assigned as both advisors and examiners at this level for post graduate students;

$>$ There should be monitoring an evaluations system for the timely progress of the researchers by the heads of departments, schools and colleges, SGS, institutional quality, and academic and research vice presidents as well, and even these sections or units of work should have a plan of orienting the researchers on the right time;

$>$ The instructors should be capacitated on the research from time to time through different capacity building trainings both abroad and in the country regularly and periodically particularly about advanced research;

$>$ It is better if the titles are evaluated, selected and approved from the very beginning to students by the concerned bodies at the department so that to make students have enough time for their research; 
The right evaluators with good history and knowledge of evaluation should be assigned so that to avoid the frustration on the part of the candidates;

$>$ It is better if the advisors are not assigned from far away universities and from irrelevant disciples; or it is better if the very right persons are assigned as advisors based on their area of specialization;

$>$ There should be language training to promote the skills of language -both writing and speaking;

$>$ It is better if the advanced training on research for instructors provided by the professional both inside the country and abroad through different modalities of training, for instance, with universities who already created partnership with Wolaita Sodo University;

$>$ Language training related with research should be offered for the students of this level from the beginning of their study;

$>$ It is better if the institution allocates researchers adequate financial resources, material resources, and time as well to make the quality the theses high.

\section{References}

Adams, G. et al. (1994). Dissertation Research in public Administration and cognate fields: An Assessment of methods and Quality, public Administration review, 54(6).

Baron, M. (2010). Guideline for writing Research Proposals and Dissertations, Division of Educational Administration, University of South Dakota: USA

Best, W.J. and V.J.( 2003). Research in Education, New Delhi: Prentice Hall.

Cohen, L. et al. (1980). Research methods in Education. London: Crumb Helm

Creswell, J. W. (2009). Research Design: Qualitative, quantitative, and mixed methods approaches (3rd ed.). Thousand Oaks, CA: Sage.

Gay, L. et al. (2012). Educational Research. Florida: Late of Florida International University, PEARSON.

Kothari, C. (1985). Research Methodology: Methods and Techniques(2nd edn.). New Delhi: Wishaw a PRAKASHAN.

Strydom, H. (2011). Ethical aspects of research in the social sciences and human service professions. In A. S. de Vos, H. Strydom, C. B. Fouche, \& C. S. L. Delport (Eds.), Research at grass roots (pp.113-129). Pretoria, South Africa: Van Schaik

Tuckman, B.(1972). Conducting Educational Research. New York: Harcourt Brace Jovanovich, Inc.

Wassenaar, D. (2010). Ethical issues in social science research. In M. Terre Blanche, K. Durrheim, \& D. Painter (Eds.), Research in practice: Applied methods for social sciences (pp. 60-79). Cape Town, South Africa: University of Cape Town Press. 